\title{
Improving Aileron Effectiveness Based on Changing the Position of Aileron Connectors
}

\author{
Ju Qiu ${ }^{1}{ }^{1}$ and Haisong Ang ${ }^{2}$ \\ ${ }^{1}$ Beijing Aeronautical Science \& Technology Research Institute (BASTRI) of Commercial Aircraft Corporation of China \\ Ltd. (COMAC), Future Science and Technology Park, Changping District, Beijing 102211, China \\ ${ }^{2}$ Aerospace Engineering, Nanjing University of Aeronautics and Astronautics, No. 29, Yudaojie, Qinhuai District, \\ Nanjing 210016, China \\ Correspondence should be addressed to Ju Qiu; juice_ju@sina.com
}

Received 24 January 2019; Accepted 2 April 2019; Published 4 June 2019

Academic Editor: Santiago Hernández

Copyright (C) 2019 Ju Qiu and Haisong Ang. This is an open access article distributed under the Creative Commons Attribution License, which permits unrestricted use, distribution, and reproduction in any medium, provided the original work is properly cited.

\begin{abstract}
In this paper, the design concept of the aileron with a fixed connector and a moving connector has been explored due to the improvement of aileron effectiveness. As usual, aileron reversal or the blocking phenomenon of multijoint fixed ailerons is a hard nut to crack. In the present research, in order to improve aileron effectiveness, several examples are studied. The connection position influences the stress, displacement, load distribution, and control effectiveness of the aileron or critical flutter speed. As the joint positions are different, the wing-aileron connection stiffness is also changing. The sample of the beam shows the weight reduction. The plate simulation indicates the decreased deformation and the better load distribution. The aileron trimming demonstrates the improvement of aileron effectiveness. And the flutter speed coupled with the aileron is different. All of these examples indicate the feasibility of this new concept of the aileron design, which means improving aileron effectiveness based on changing the position of aileron connectors. Finally, three different modes for wing-aileron connections are suggested for reference.
\end{abstract}

\section{Introduction}

An aileron is a hinged flight control surface usually forming part of the trailing edge of each wing of a fixed-wing aircraft. Ailerons are used in pairs to control the aircraft in roll or combine the elevator for the aircraft's pitching trim, which normally results in a change in flight path due to the tilting of the lift vector. Ailerons are quite often situated near the wing tip but may sometimes also be situated near the wing root. Modern large transport aircraft (e.g., bomber Boeing B-2) also have a second pair of ailerons on their wings, and the terms "outboard aileron" and "inboard aileron" are used to describe these positions, respectively.

With the development of the control surface system, several combination types of ailerons occur. Combining an aileron and a flap is called a flaperon, which has the functions of both ailerons and flaps. The ailerons are combined with the elevators to form an elevon, which is applied to delta- winged aircraft. Some high-speed aircraft are equipped with inner ailerons to reduce the torsional deformation of the wings caused by the deflection of the ailerons. Therefore, the internal ailerons are also called high-speed ailerons.

In the design process of an aileron, four parameters need to be determined. They are the aileron planform area, aileron chord/span, maximum up and down aileron deflection, and location of the inner edge of the aileron along the wingspan. Based on the statistics, about 5 to 10 percent of the wing area is devoted to the aileron, the aileron-to-wing-chord ratio is about 15 to 25 percent, the aileron-to-wingspan ratio is about 20-30 percent, and the inboard aileron span is about 60 to 80 percent of the wingspan.

A number of aircraft when flying near their maximum speed are subject to an important aeroelastic phenomenon. No real structure is ideally rigid, and it has static and dynamic flexibility. Wings are usually produced from aerospace materials such as aluminum and composite materials 
and have structures which are flexible. This flexibility causes the wing to not be able to maintain its geometry and integrity, especially in high-speed flight operations. This phenomenon which is referred to as aileron reversal negatively influences the aileron effectiveness.

Generally, in order to avoid this situation, the stiffness of the aileron surface is often increased or the number of support joints for the aileron is increased. Not only will this raise the weight of the aileron structure, but by the use of multijoint fixed ailerons, such as the General Dynamics F-16 Fighting Falcon with a short wingspan and large aileron, the axis of the aileron shaft will also be bent, which will affect the flexibility of the operation, and even the jam phenomenon, when the wing is deformed in flight. However, in an aircraft with a long wingspan and several small ailerons, such as the B-2, it can prevent the blocking phenomenon.

Since then, lots of scientists and experts had been engaged in the design of ailerons, such as the weight loss of ailerons and the improvement of aileron effectiveness.

In the last century, many authors introduced the activecontrol conception of ailerons and morphing-wing aileron controllers from a 2-D wing to a 3-D one. Jacobs [1] investigated aileron effectiveness for subsonic energy-efficient transport models with a high-aspect-ratio supercritical wing. He first proposed that the ailerons were designed as a preliminary active-control concept with gust-load alleviation, maneuverload alleviation, and a flutter-suppression system. After that, Suleman et al. [2] presented the results of wind tunnel testing performed on a three-dimensional adaptive wing structure. The aeroelastic performance of the wing using traditional, aerodynamic control surface methods was compared to the results obtained using piezoelectric actuators bonded to the skins of the wing. After 10 years, Pankonien et al. [3] indicated that smart materials had been widely applied in morphing aerospace structures, improving performance and reducing weight and mechanical complexity when compared to conventional actuators. A year later, Pankonien et al. [4] proposed the concept of the Synergistic Smart Morphing Aileron (SSMA), which combined the fast, conformal actuation of Macro-Fiber Composites (MFC) with the high specific work of shape memory alloys (SMA). Additionally, the SSMA demonstrated the ability to mitigate aeroelastic effects and flow separation near stall via novel reflex actuation. In the same year, Koreanschi et al. [5] designed a morphing wing-with-aileron system. The aileron shapechanging methods were evaluated by them according to their improvement of the lift coefficient and their delay of the boundary layer detachment. Makarov and Pavlenko [6] used computational fluid dynamics to model the flow field over several variants of an aileron on a high-lift wing airfoil. The hinge moment coefficient was obtained. And then, Vincent and Botez [7] demonstrated a multidisciplinary project for morphing-wing aileron control.

For a missile control system, Johnson and Lind [8] showed sweeping of the model through many ALPHA/BETA orientations, while the control system automatically trimmed out the three primary moments. It also produced trim maps of normal, side, and axial forces as well as the pitch, yaw, and roll commands required for the trim.
As for UAVs' and MAVs' control, Sellers and Corder [9] showed that a complete pass at a high angle-of-attack was performed to establish the trim position for all control surfaces; Halland and Mason [10] demonstrated that a basic aerobatic flight maneuver from which other maneuvers could be derived was the aileron roll.

According to the transport aircraft's aileron design, Pratheepan and Bruce [11] pointed out that the cantilever wing with an aileron control surface was designed and its effects on aerodynamic and structural characteristics were computed.

Lastly, Elham and van Tooren [12] introduced the wing box structure of commercial aircraft, and the effect of aileron effectiveness on it was investigated by them.

The above researches considered the aileron control, function, and tests and discussed some advantages and disadvantages. In the current study, it focused on changing the locations of the aileron joints to obtain the best effectiveness of the aileron.

\section{Static and Dynamic Aeroelastic Analyses of Ailerons}

The control force or moment of the aileron is related to the height (air density), the speed, and the overload (acceleration) of the aircraft's flight. The aileron manipulation falls within the flight envelope each time. Simultaneously, the flight of the aircraft is free for flutter in the flight envelope, when the control surfaces deflect.

2.1. Static Aeroelastic Trim. In general, static aeroelastic analysis has three approaches. Here, two of them are introduced, namely, the compliance method and the modal method.

2.1.1. Compliance Method. The influence coefficient of the flexibility of the wing surface is obtained by means of the structural finite element analysis method. Based on the balance between the elastic force of the wing structure system and the steady aerodynamic force, the characteristic equation of static divergence analysis by the flexibility method is established. The static aeroelastic equation of this method can be expressed as

$$
\left(\mathbf{T}_{\mathrm{cs}, z \mathrm{z}} \mathbf{C}_{\mathrm{zz}} \mathbf{T}_{\mathrm{As}}^{T} \mathbf{A}_{\mathrm{s}} \mathbf{T}_{\mathrm{cc}, \theta}-\frac{\mathbf{I}}{\mathbf{q}_{\mathrm{D}}}\right) \mathbf{u}_{\mathrm{c}}=0
$$

where $\mathbf{u}_{c}$ is the deformation vector of aerodynamic grid control points, $\mathbf{T}_{\mathrm{cs}, \mathrm{zz}}$ is the transformation matrix that converts the displacement vector of the structural node, $\mathbf{C}_{\mathrm{zz}}$ is the compliance influence coefficient matrix based on nodes, $\mathbf{T}_{\text {As }}^{T}$ is the transposition matrix, $\mathbf{A}_{\mathrm{s}}$ is the steady aerodynamic influence coefficient matrix, $\mathbf{T}_{\mathrm{cc}, \theta}$ is the transformation matrix, $\mathbf{q}_{\mathrm{D}}$ is the divergent dynamic pressure, and $\mathbf{I}$ is the identity matrix.

When the characteristic equation (1) is solved, the maximum eigenvalue of the matrix, $\mathbf{T}_{\mathrm{cs}, \mathrm{zz}} \mathbf{C}_{\mathrm{zz}} \mathbf{T}_{\mathrm{As}}^{T} \mathbf{A}_{\mathrm{s}} \mathbf{T}_{\mathrm{cc}, \theta}$, can be found, whose reciprocal is the critical divergent dynamic pressure. 
2.1.2. Modal Method. The modal method selects the superposition of the required first few natural modes (under the condition of guaranteeing accuracy) to describe the deformation of the wing surface, which is different from the physical displacement deformation vector of the nodes selected by the flexibility method. The characteristic equation of static divergence analysis here is

$$
\left(\overline{\mathbf{K}}-\mathbf{q}_{D} \overline{\mathbf{A}}_{\mathrm{s}}\right) \mathbf{q}=0
$$

where $\overline{\mathbf{K}}$ is the generalized stiffness matrix, $\overline{\mathbf{A}}_{\mathrm{s}}$ is the generated steady aerodynamic influence coefficient matrix, and $\mathbf{q}$ is the generalized coordinate matrix.

When the characteristic equation (2) is solved, the minimum eigenvalue of the matrix is found, which is the critical divergent dynamic pressure.

2.2. Symmetric Longitudinal Trim. The different pitching trim cases for the aileron and elevator are listed in Table 1.

2.3. Antisymmetric Rotational Trim. The following chart (see Figure 1) shows the typically rolling trim of the aileron.

2.4. Aileron Effectiveness. Factors affecting the design of the aileron are the required hinge moment, aileron effectiveness, aerodynamic and mass balancing, flap geometry, aircraft structure, and cost. One of the most important factors is aileron effectiveness, which is a measure of how effective the aileron deflection is in producing the desired rolling moment or pitching moment.

Aileron effectiveness is defined as follows:

$$
\eta_{\mathrm{a}}=\frac{\left(\partial C_{\mathrm{l}} / \partial \delta_{\mathrm{a}}\right)_{\mathrm{e}}}{\left(\partial C_{\mathrm{l}} / \partial \delta_{\mathrm{a}}\right)_{\mathrm{r}}}
$$

where $C_{1}$ is the roll or pitch moment coefficient of the aircraft, $\delta_{\mathrm{a}}$ is the aileron deflection angle, the subscript e represents elasticity, and the subscript $\mathrm{r}$ represents rigidity.

In the previous studies, we observed the relationship between aileron effectiveness and flight speed (see Figure 2) when the aileron deflection angle was fixed.

Also, we saw the relationship between aileron effectiveness and flight altitude (see Figure 3), as the aileron deflection angle was fixed.

From Figure 3, when the flight altitude is rising, aileron effectiveness also increases. However, while flight speeds are going up, aileron effectiveness goes down.

2.5. Flutter Analysis. The inherent characteristics of the overall structure caused by the support stiffness weakness of ailerons will inevitably lead to flutter or divergence ruin.

In the present research, the P-K method is used to calculate the flutter speeds, which can be written as

$$
p^{2} \overline{\mathbf{M}} \mathbf{q}+\overline{\mathbf{K}} \mathbf{q}-\frac{1}{2} \rho V^{2} \overline{\mathbf{A}} \mathbf{q}=0
$$

where $p$ is the eigenvalue which is equal to $\gamma \omega+\omega i$ (nondimensional Laplace), $\overline{\mathbf{M}}$ is the generalized mass matrix, $\overline{\mathbf{K}}$ is
TABLE 1: Trim cases.

\begin{tabular}{lccc}
\hline Cases & Load factor & Flight speed (Mach) & Flight altitude (ft) \\
\hline 1 & $1 \mathrm{~g}$ & 0.6 & 12000 \\
2 & $1 \mathrm{~g}$ & 1.2 & 300 \\
3 & $1 \mathrm{~g}$ & 1.2 & 12000 \\
4 & $4 \mathrm{~g}$ & 1.2 & 12000 \\
\hline
\end{tabular}

the generalized stiffness matrix, $\mathbf{q}$ is the vector of generalized coordinates, and $(1 / 2) \rho V^{2}$ is the flight dynamic pressure.

By use of the flutter equation to compute the flutter speed, plots of $V$ versus g can be used to determine the flutter speed(s) (where damping goes through zero to positive values).

\section{Influences of the Locations of Joints for Support Stiffness}

As can be known, the difference in support stiffness will affect the distribution of loads. In the present research, several examples will demonstrate it.

3.1. Example of Weight Reduction. A solid beam was 3 meters long, whose radius was $0.006 \mathrm{~m}$. The material is steel, the density is $7800 \mathrm{~kg} / \mathrm{m}^{3}$, Young's modulus is $2.1 E 10^{11}$, and the Poisson ratio is 0.3 . The load, $200 \mathrm{~N}$, was applied at the left end, and the other one, $100 \mathrm{~N}$, was applied at the right end. In Case 1, the fixed support was located in the middle of it. In Case 2, the fixed support was situated at 1/3 of it. Figure 4 shows two cases.

Through static analysis and calculation, we can see Figure 5.

As can be seen from Figure 5, the highest stress in Case 1 appears at the central constraint, with a value of $1710 \mathrm{MPa}$, while the peak stress of Case 2 occurs at $1 / 3$ of it, which is $1180 \mathrm{MPa}$. The reason is listed as follows: in Case 2, the moment is exactly balanced at the constraint point and only the shear force of $300 \mathrm{~N}$ exists. But in Case 1, there is not only the shear force at the constraint point but also the unbalanced bending moment so the stress is larger than that in Case 2.

And then, the radius of the beam under Case 2 was changed to $0.00529 \mathrm{~m}$ and Case 1 remained unchanged. Static analysis was carried out. The results are listed in the following Figure 6.

As can be seen from Figure 6, the highest stress in Case 1 appears at the central constraint, with a value of $1710 \mathrm{MPa}$. In Case 2, however, the peak stress arrives at $1720 \mathrm{MPa}$ at the fixed point. At this point, the maximum stress of the two beams is almost the same, but the beam radius in Case 1 is $0.006 \mathrm{~m}$, and in Case 2, it is $0.00529 \mathrm{~m}$, so the weight in Case 2 is reduced by $22.66 \%$.

3.2. Example of Support Load Distribution. Two plates with the same size and thickness were used in static analysis. And the materials were similar. The loading position and applied forces on those two plates were identical, except that the constrained positions on the left side were different. The fixed points in Case 1 were at one-quarter 
Antisymmetric case: trim parameters
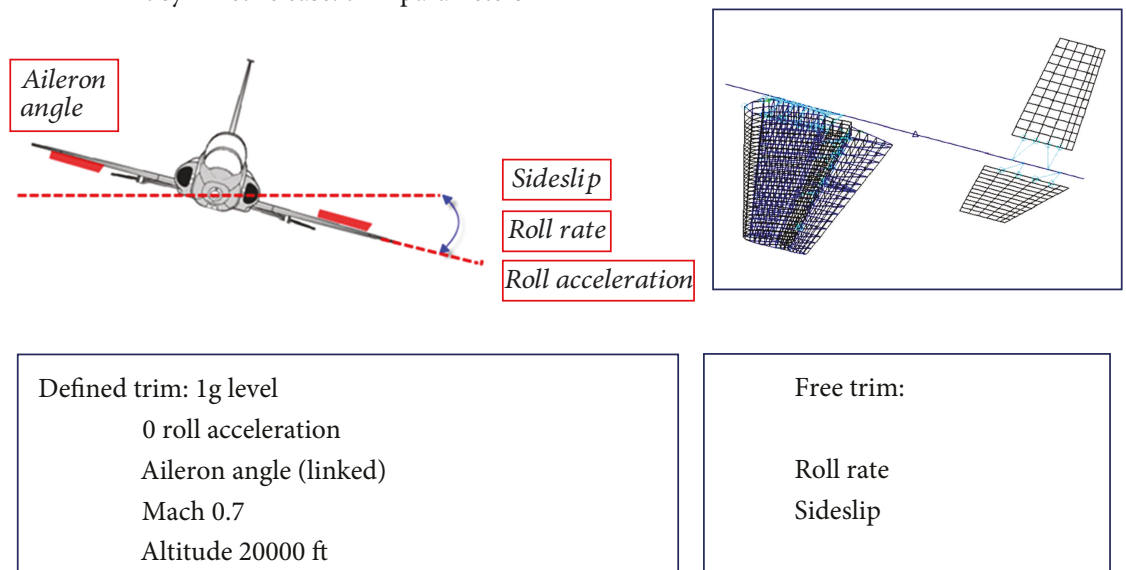

Free trim:

Roll rate

Sideslip

FIgURe 1: Antisymmetric trim for ailerons.

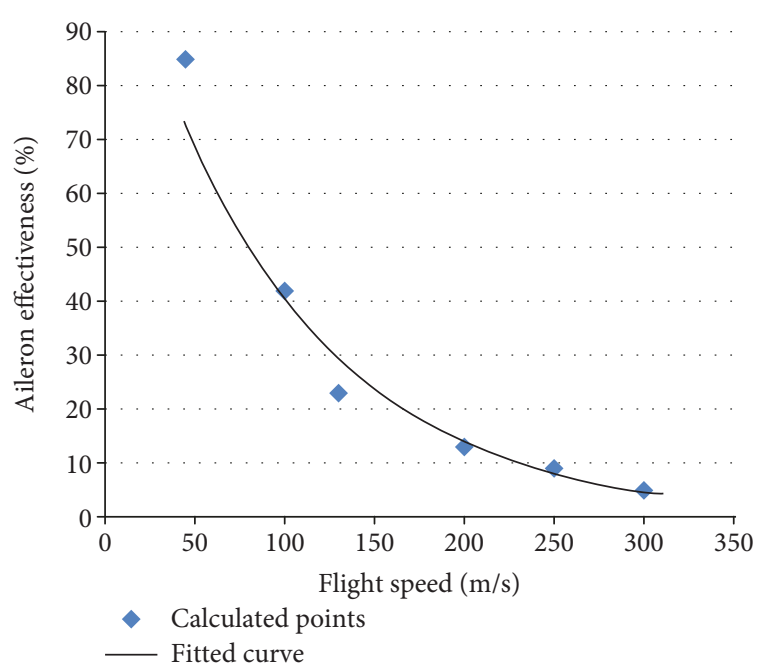

Figure 2: Aileron effectiveness vs. flight speed.

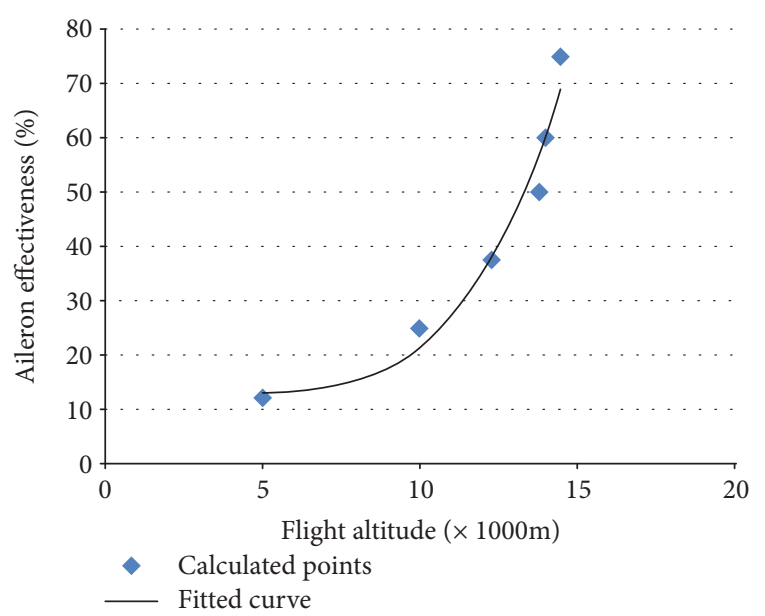

Figure 3: Aileron effectiveness vs. flight altitude. and three-quarters of the left side, while in Case 2, they were located at one-third and two-thirds. Figure 7 shows FEMs and boundary conditions.

After static analysis, the compared results are indicated in Table 2.

From Table 2, the stress is similar; Case 1 has approximately 29 percent less displacement than Case 2; in Case 1, the support loads of two joints are distributed reasonably which are all in the same magnitude, and the load distributions in Case 2 are not reasonable, in which their load ratio is more than 3 times.

3.3. Example of Aileron Effectiveness. The two-beam structure was used in the wing, which had 19 ribs. The wing semispan was more than $10 \mathrm{~m}$. The GFEM (Global Finite Element Model) was employed to express it. Please see Figure 8.

There were six potential joints in this model (see Figure 9).

From Figure 9, the wing was connected with the aileron by beam elements. The rotational DOF of the beams along the aileron axis was released.

3.3.1. Static Aeroelastic Symmetric Trim of the Aileron. The wing-aileron connection is supposed to have a pitching trim, which is like the elevon's function. The root of the wing was symmetrically supported (in this model, we constrained 2, 4, and 6 directions), when static aeroelastic trim was performed.

The aerodynamic meshes of the main wing surface, the aileron, and the flap were established in Figure 10, which were coupled with the corresponding structures. The rotation axis and operating surface of the aileron were also defined.

Flight velocity and air density were defined, and the deflection angle of the aileron was set. According to different connecting positions between the wing and aileron, three cases were built up in Figures 11-13. Please note that one of the joints was fixed.

In the current study, to simplify the calculation and analysis, the aileron deflection was $5^{\circ}$ and the static aeroelastic pitching trim was carried out. The loads and moments of 


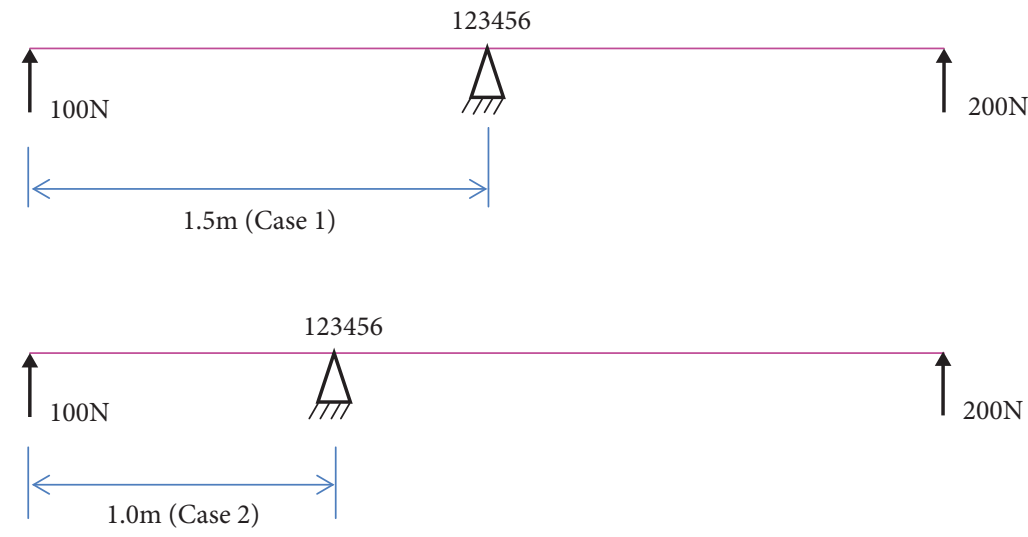

Figure 4: Finite element models for two cases.

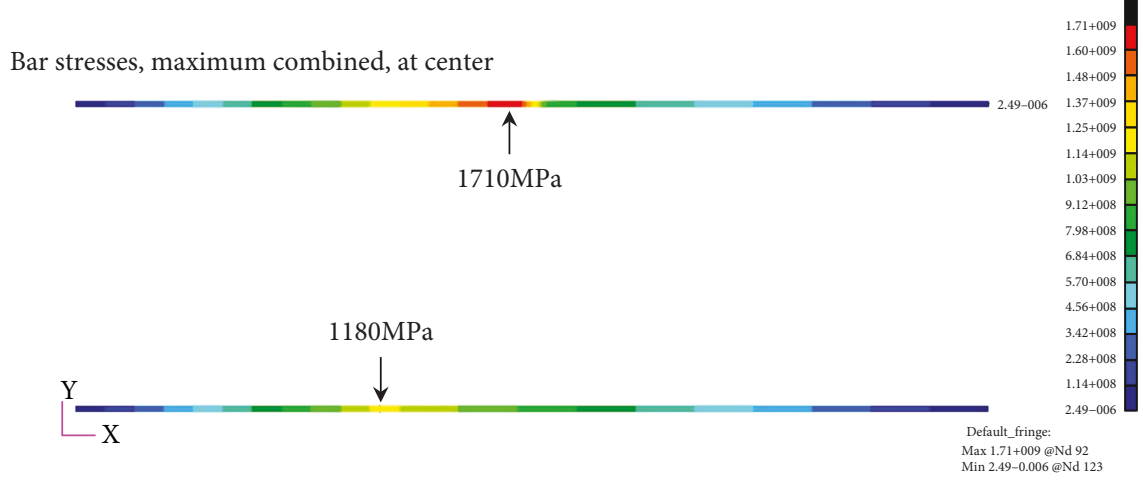

FIGURE 5: Stress contour plot.

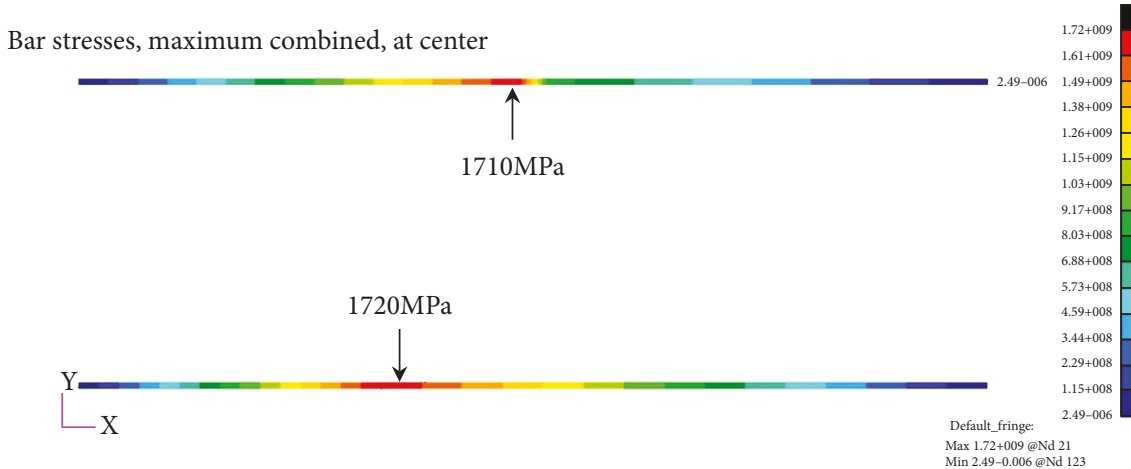

Figure 6: Stress contour plot.
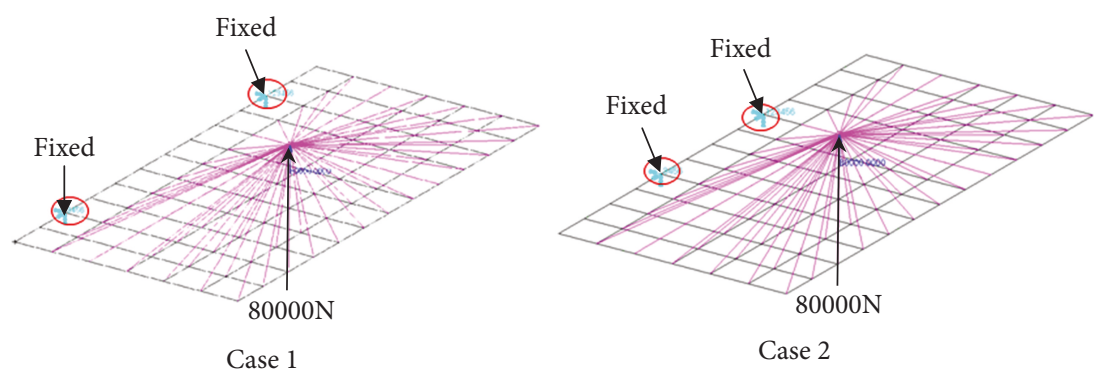

Figure 7: FEMs of plates. 
TABle 2: Comparison of two cases.

\begin{tabular}{lcccc}
\hline Case & Stress (Mpa) & Displacement $(\mathrm{mm})$ & Joint 1 $(\mathrm{N})$ & Joint 2 (N) \\
\hline 1 & 435 & 6.26 & 21310 & 58690 \\
2 & 439 & 8.83 & 6020 & 73980 \\
\hline
\end{tabular}

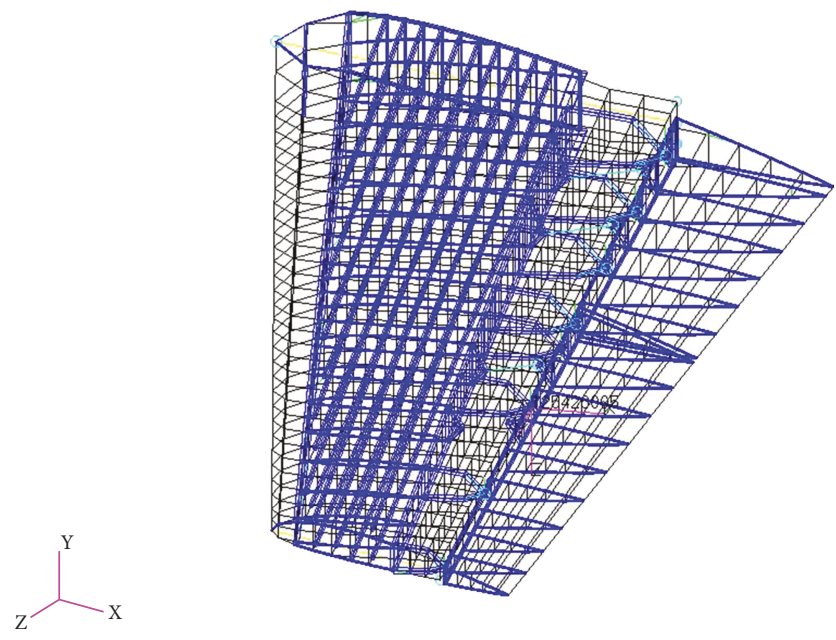

Figure 8: The GFEM of the wing.

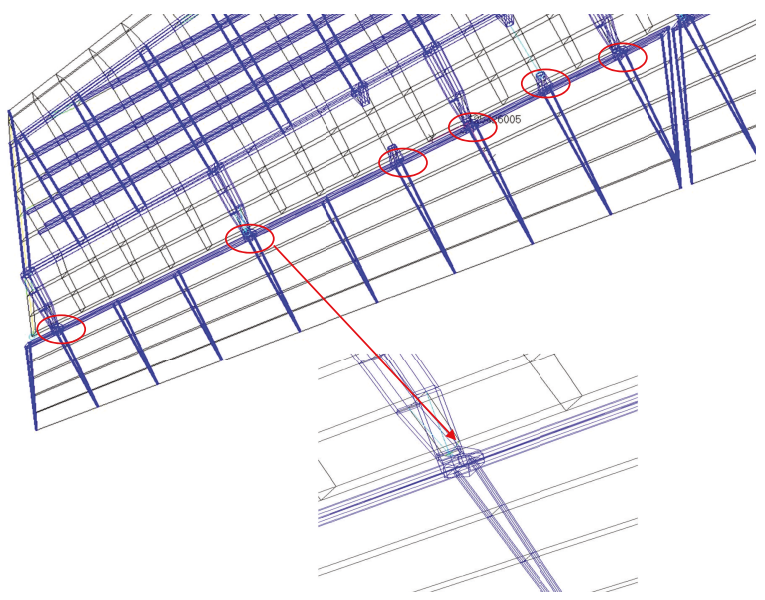

FIgURE 9: Six wing-aileron connectors.

the rigid and elastic ailerons were obtained, and the aileron effectiveness was calculated, which is listed in Table 3.

Case 2 was selected as the location layout of the wingaileron joint under the flight condition.

3.3.2. Example of Static Aeroelastic Antisymmetric Trim of the Aileron. Suppose that the wing and tails have a rolling trim. The wing has an aileron and a flap. The structures of the horizontal tail and vertical tail are equivalent to the plate elements. The horizontal tail contains the elevator, and the vertical tail includes the rudder. The fuselage is expressed by an equivalent beam and mass elements. The FEM is shown in Figure 14. Antisymmetric constraints were set.

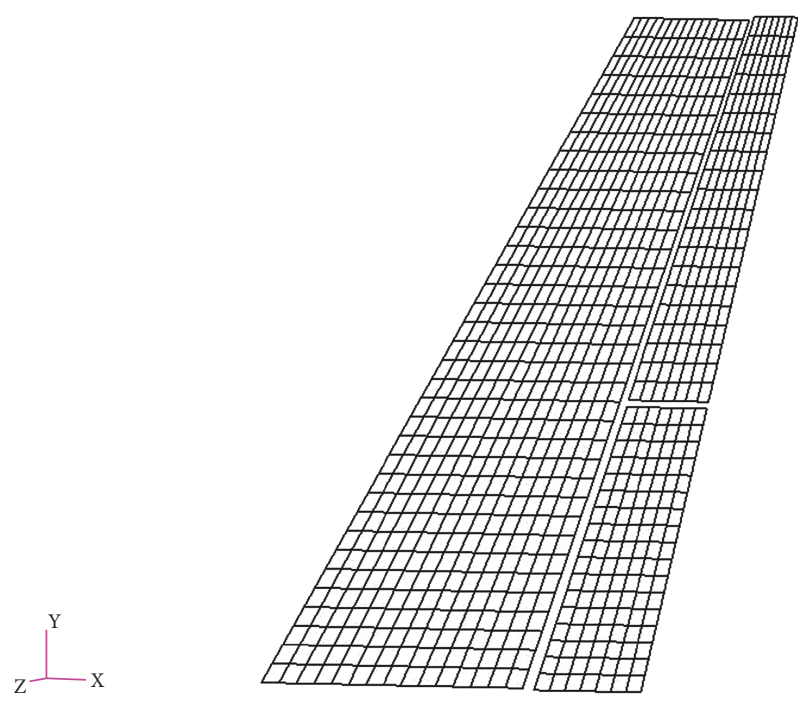

FIGURE 10: Aerodynamic meshes of the wing.

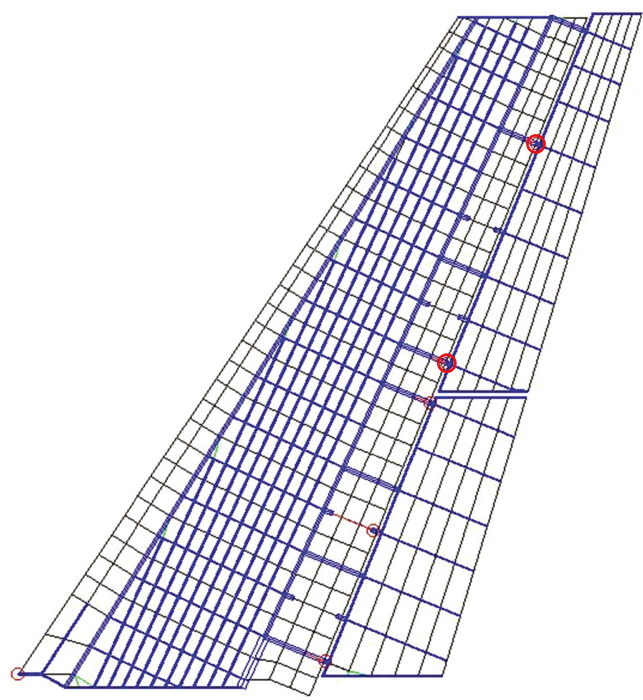

FIgURE 11: Wing-aileron connection in Case 1.

The aerodynamic meshes of the main wing and tail surface, the aileron, the flap, the elevator, and the rudder were established in Figure 15 and were defined by the coupling with the corresponding structures. The rotation axis and operating surface of the aileron, elevator, and rudder were also defined.

Two joints were used in the wing-aileron connection, which was situated at Case 1, Case 2, and Case 3 . The aileron deflection was $15^{\circ}$, and the static aeroelastic rolling trim was carried out. The loads and moments of the rigid and elastic ailerons were obtained, and the aileron effectiveness was calculated, which is listed in Table 4.

Case 3 was selected as the location layout of the wingaileron joint under the flight condition.

3.4. Example of Flutter Analysis. Generally, the vibration analysis is done before the flutter analysis. 


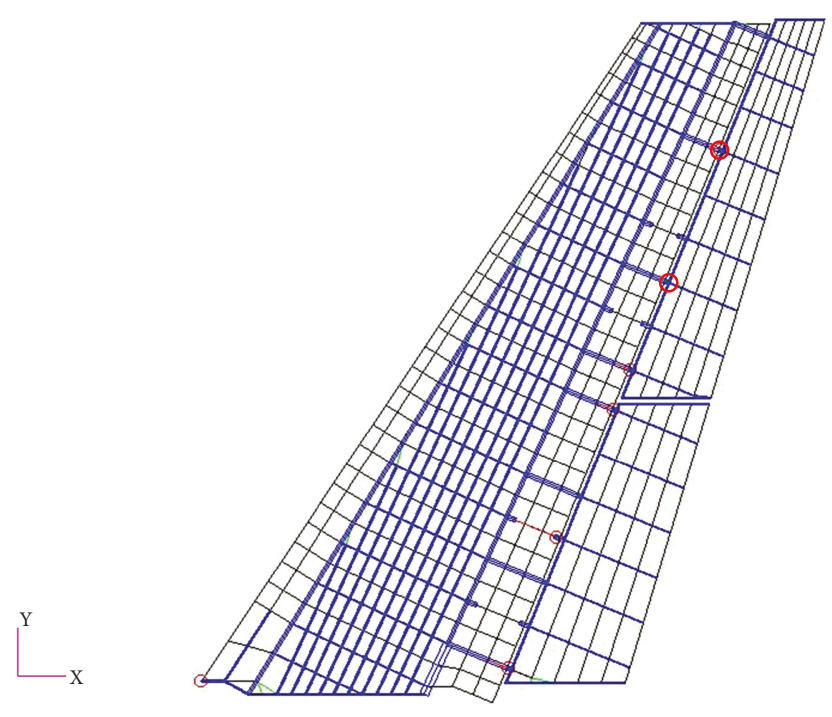

FIgURE 12: Wing-aileron connection in Case 2.

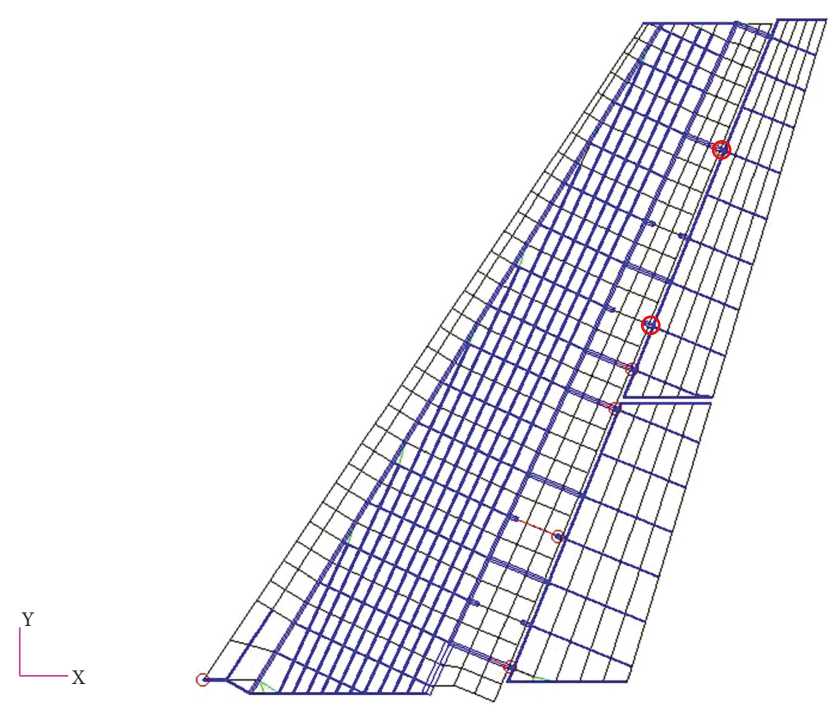

FIgURE 13: Wing-aileron connection in Case 3.

TABLE 3: Comparison of aileron effectiveness.

\begin{tabular}{lc}
\hline Cases & Aileron effectiveness $\eta_{\mathrm{a}}(\%)$ \\
\hline 1 & 34.58 \\
2 & 88.29 \\
3 & 71.25 \\
\hline
\end{tabular}

3.4.1. Vibration Analysis. The end of the wing was clamped. The first twenty modes of the model (see Figure 16) were analyzed by the Lanczos method. And these significant 10 vibratory modes were selected in the flutter solution. These modes included the bending and translational modes of the wing; the in-plane and out-plane bending; and torsion modes of the flap and aileron, such as the flap translation; and the aileron deflection. Case 1 was taken as an example.
The 10 selected modes for flutter analysis are listed in Table 5.

From Table 5, we can see that the flap and aileron modes are inserted into the classic bending and torsional modes of the wing, when the control surfaces are released. This will make the control surface coupling flutter ahead of schedule.

3.4.2. Flutter Analysis. For flutter analysis, the unsteady aerodynamic forces were obtained using Doublet Lattice Method (DLM) for flight. The unsteady aerodynamic forces upon the simulated beam were ignored. Aerodynamic trapezoidal panels of the wing are described in Figure 10.

Through the flutter analysis, the $V$-g and $V$-f curves of Case 1 are shown in Figures 17 and 18, when $M=1.3$ and density ratio $=0.6$.

In Figure 17, damping of the second torsional mode of the aileron changes from the negative value to the positive at the speed of $410 \mathrm{~m} / \mathrm{s}$, and Figure 18 presents frequencies of the first bending mode of the wing and the second torsional mode of the aileron which are trying to go toward the same value at the speed of $410 \mathrm{~m} / \mathrm{s}$, that is, around 1.3 $M$. At $410 \mathrm{~m} / \mathrm{s}$, the critical flutter occurs, which is greater than the maximum flight speed.

Through Figures 17 and 18, when the first bending mode and the translational mode of the flap are coupled, the flutter speed appears to reach $425 \mathrm{~m} / \mathrm{s}$. While the first bending mode and the first torsional mode of the aileron are coupled, the flutter speed may be higher.

By doing steps like Case 1, we can obtain the critical flutter speed for Case 2 and Case 3, which is listed in Table 6.

\section{Conclusions}

The present research introduces several examples to highlight the importance of the joint positions. The beam example indicates that the different connection location can reduce the stress and weight of the structure. The second one, the plate simulation, demonstrates that it has the different joint position, which makes the deformation less and the distribution of the connection forces more appropriate. In the third one, three cases for wing-aileron connections are trimmed over the flight envelope. The best aileron effectiveness is chosen from the different support locations of the ailerons. Finally, the flutter speeds are achieved in three cases, which indicates that the wing surface is free for flutter, coupled with the wing bending and the aileron torsion.

Most importantly, we compare three configurations of connection locations of the ailerons and select the optimal one. Furthermore, the selected case of the aileron configuration offers reduced costs, schedule, and weight.

\section{Final Remarks}

This paper puts forward a kind of new concept for designing the aileron, based on changing the wing-aileron connection location. Through a fixed joint, the other one is adjusted, according to the flight conditions. It is to improve the wing connection (support) stiffness, redistribute the wing load, and reduce the elastic deformation, and therefore, the aileron 


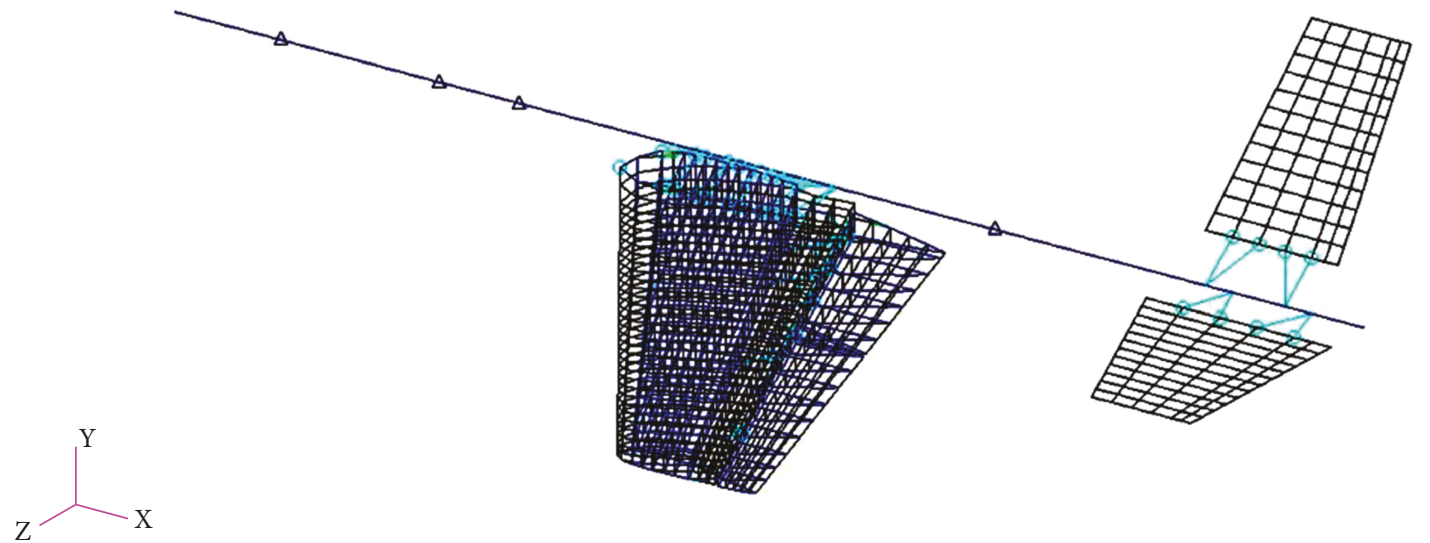

Figure 14: FEM of the wing and tails.

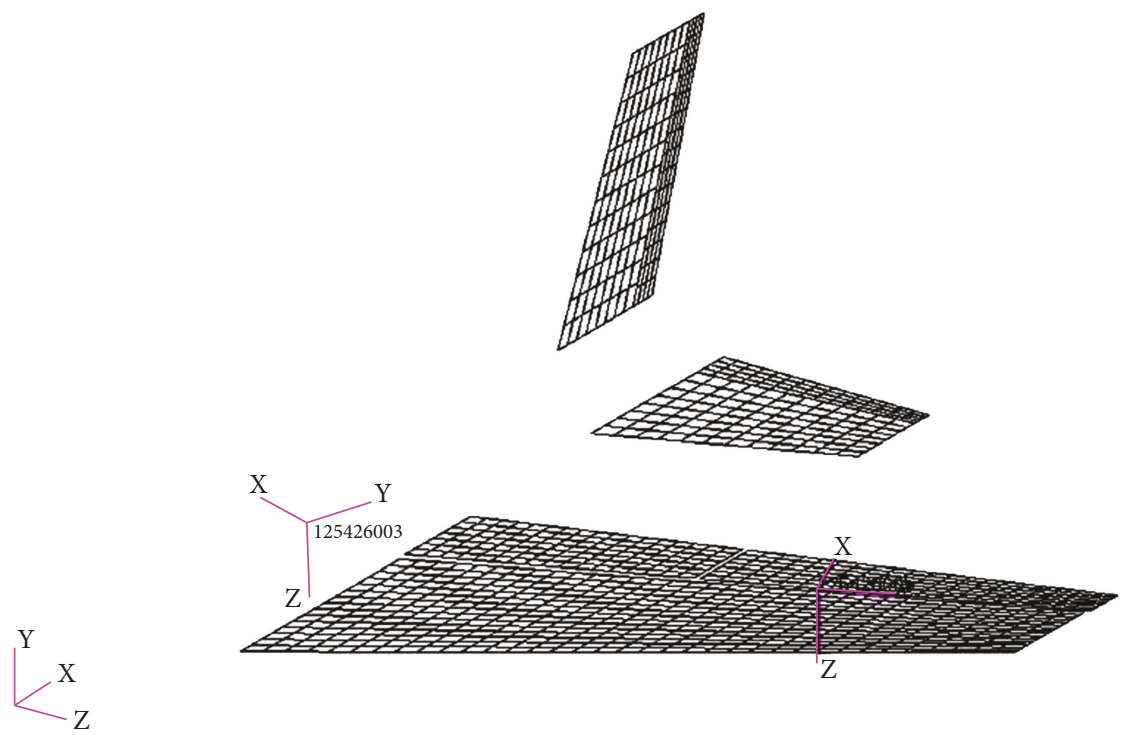

FIgURE 15: Aerodynamic meshes of the wing and tails.

TABle 4: Comparison of aileron effectiveness.

\begin{tabular}{lc}
\hline Cases & Aileron effectiveness $\eta_{\mathrm{a}}(\%)$ \\
\hline 1 & 25.15 \\
2 & 54.78 \\
3 & 61.27 \\
\hline
\end{tabular}

effectiveness enhances. Moreover, the following advantages are shown.

(1) The rigidity of the structure is increased, when we adopt a multipoint connection, just like the conventional wing-aileron connection; however, it is possible to bend the axis of the rotating shaft of the aileron, leading to the phenomenon of jam. This proposal suggests using a two-point connection to avoid this occurrence. Additionally, by changing the position of one of the wing-aileron joints, the connection (support) stiffness can be changed to reduce the deformation of the aileron and realize the redistribution of the wing load. As a result, it improves the aileron effectiveness

(2) Several ailerons of large aircraft can prevent the control blocking caused by the bending axis of the aileron, but it adds a set of control mechanisms and increases the processing cost

(3) By suppressing the conventional aileron reverse, we have to improve the stiffness, which increases the structural dimension and causes the weight increase; however, this proposal only changes the wing-aileron connection position and modifies the wing-aileron stiffness and the load distribution and, therefore, prevents the aileron reversal

Most importantly, the paper only proposed a conception for designing the new aileron, which had a potential function to enhance the control effectiveness. And realization 
Mode 1: Freq. $=1.6441 \mathrm{E}-5 \mathrm{~Hz}$

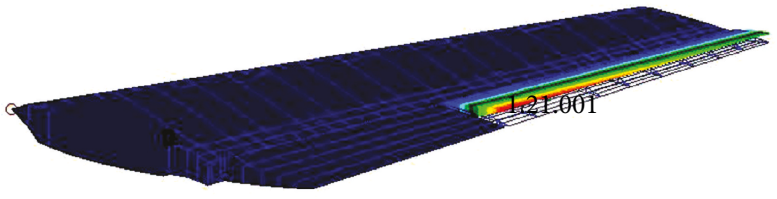

Default_Fringe:
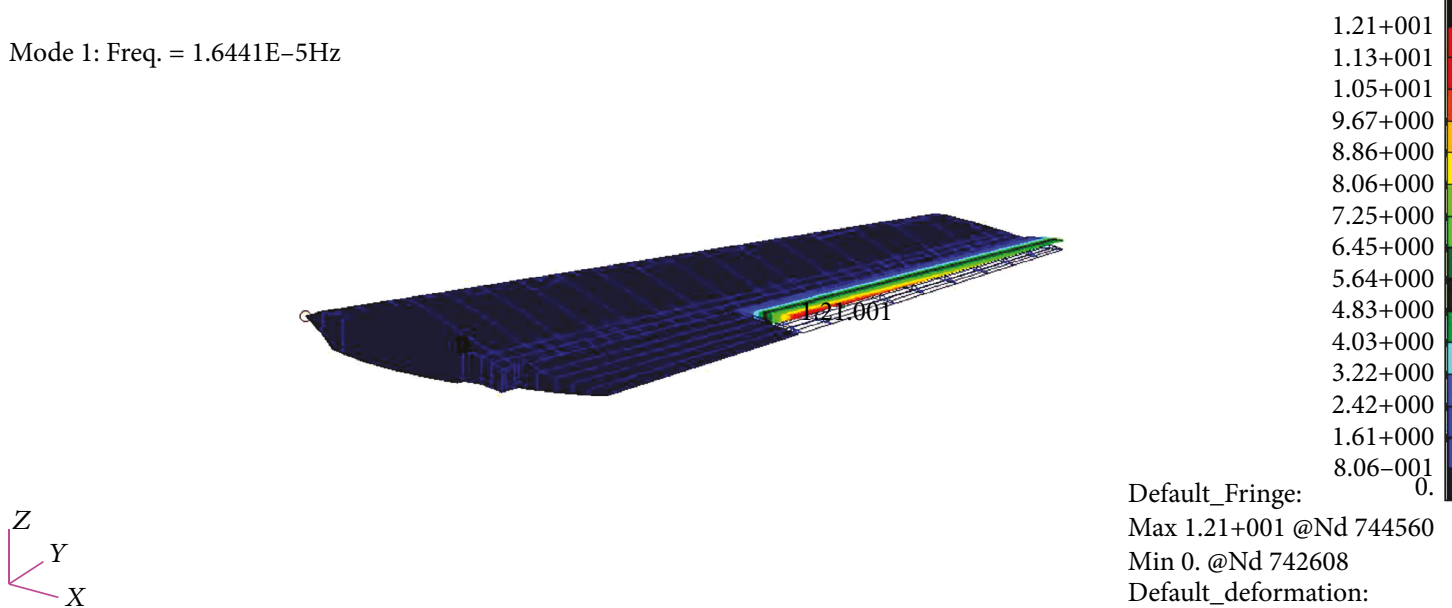

(a) 744560

Min 0. @Nd 742608

Default_deformation:

Max 1.21+001@Nd 744560

The first rigid mode of the aileron deflection

(a)

Mode 2: Freq. $=9.337 \mathrm{~Hz}$

$\sum_{X}^{Y} Z$

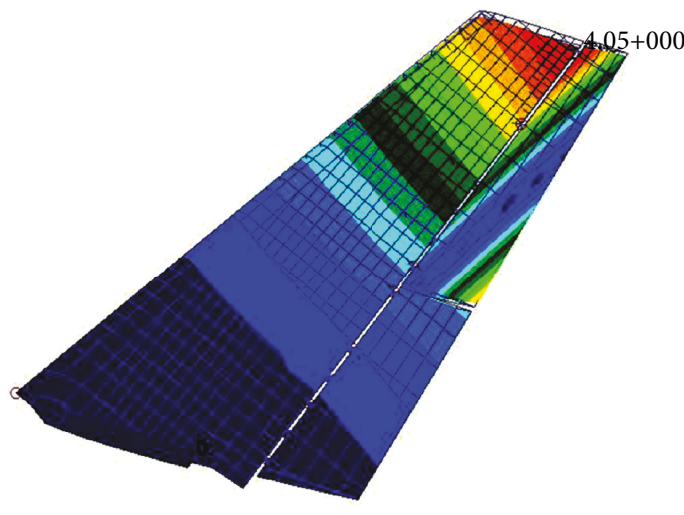

The first bending mode of the wing

(b)

\begin{tabular}{r||}
$4.05+000$ \\
$3.78+000$ \\
$3.51+000$ \\
$3.24+000$ \\
$2.97+000$ \\
$2.70+000$ \\
$2.43+000$ \\
$2.16+000$ \\
$1.89+000$ \\
$1.62+000$ \\
$1.35+000$ \\
$1.08+000$ \\
$8.10-001$ \\
$5.40-001$ \\
$2.70-001$ \\
0.
\end{tabular}

Default_Fringe:

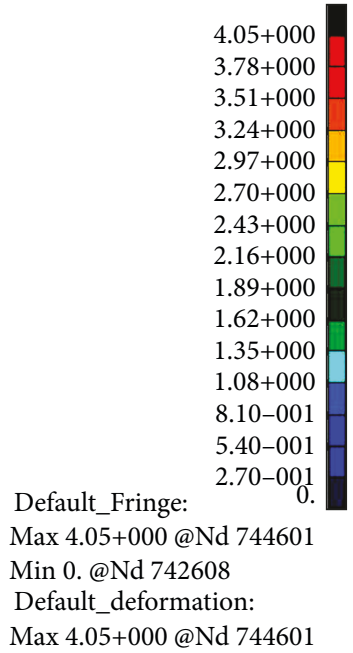

Max 4.05+000 @Nd 744601

Mode 3: Freq. $=25.732 \mathrm{~Hz}$

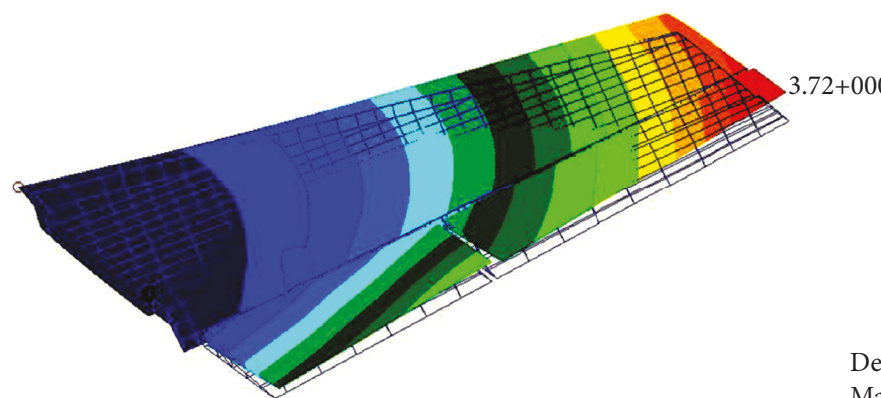
$3.72+000$
$3.47+000$
$3.22+000$
$2.97+000$
$2.73+000$
$2.48+000$
$2.23+000$
$1.98+000$
$1.73+000$
$1.49+000$
$1.24+000$
$9.91-001$
$7.43-001$
$4.95-001$
$2.48-001$
0.

Default_Fringe:

Min 0. @Nd 742608

Default_deformation:

$\mathcal{K}_{X}^{Y}$

Max3.72+000 @Nd 744617

The first translational mode of the wing

(c)

Figure 16: Continued. 
Mode 4: Freq. $=26.92 \mathrm{~Hz}$

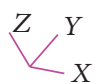

Mode 5: Freq. $=31.056 \mathrm{~Hz}$

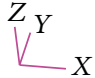

Mode 6: Freq. $=40.307 \mathrm{~Hz}$<smiles>[Y][V]</smiles>

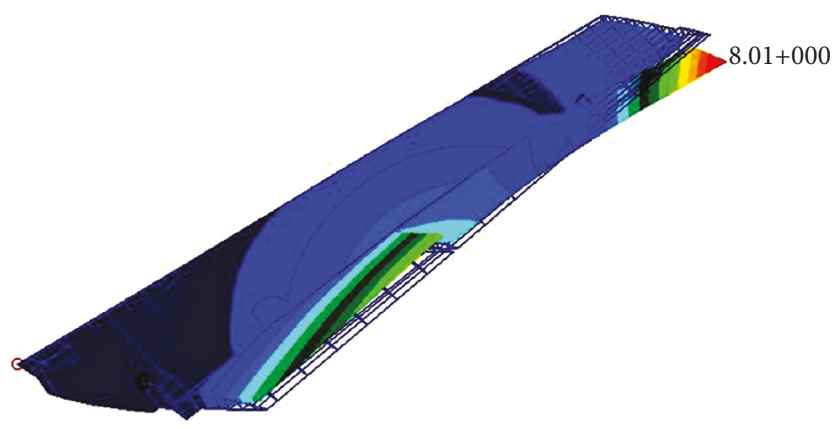

Default_Fringe:

$$
5.34-001
$$

Max 8.01+000@Nd 744617

Min 0. @Nd 742608

Default_deformation:

Max 8.01+000@Nd 744617

The flap deflection mode \& bending down of the aileron

(d)

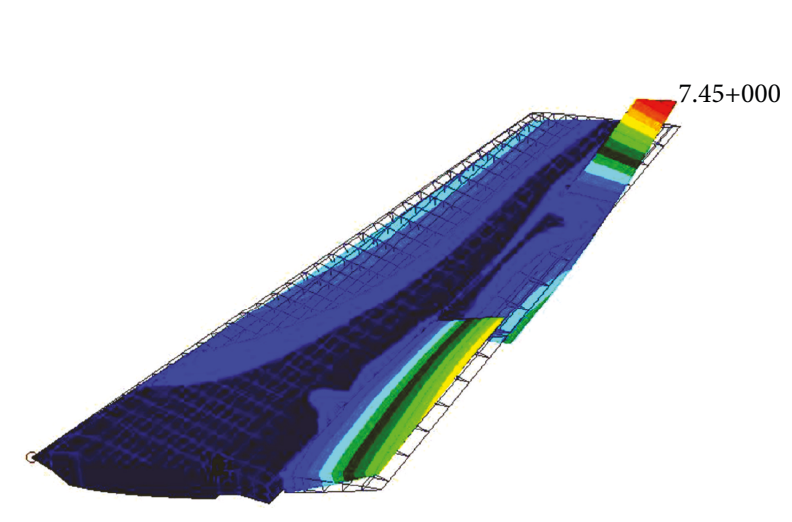

Default_Fringe:

$$
\begin{array}{r}
7.45+000 \\
6.95+000 \\
6.45+000 \\
5.96+000 \\
5.46+000 \\
4.96+000 \\
4.47+000 \\
3.97+000 \\
3.48+000 \\
2.98+000 \\
2.48+000 \\
1.99+000 \\
1.49+000 \\
9.93-001 \\
4.96-001 \\
0 .
\end{array}
$$

Max 7.45+000@Nd 744617

Min 0.@Nd 742608

Default_deformation:

Max 7.45+000 @Nd 744617

The flap deflection mode \& bending up mode of the aileron

(e)

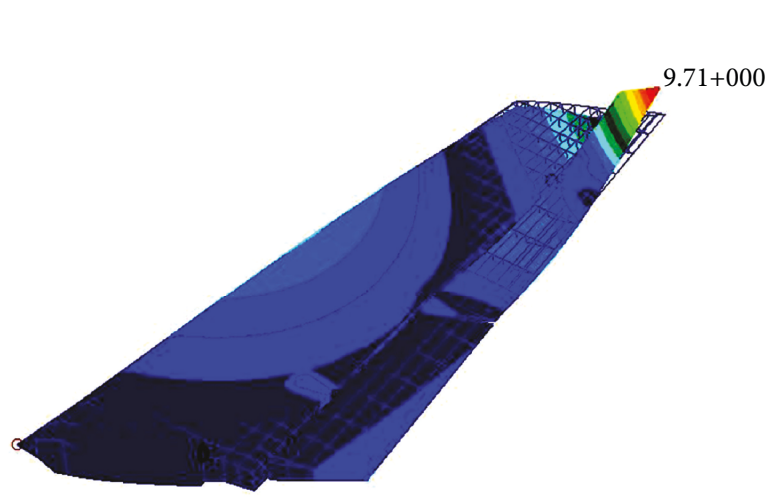

Default Fringe:

$$
\begin{array}{r}
9.71+000 \\
9.06+000 \\
8.42+000 \\
7.77+000 \\
7.12+000 \\
6.47+000 \\
5.83+000 \\
5.18+000 \\
4.53+000 \\
3.88+000 \\
3.24+000 \\
2.59+001 \\
1.94+001 \\
1.29+001 \\
6.47-001 \\
0 .
\end{array}
$$

Max 9.71+000@Nd 744617

Min 0. @Nd 742608

Default_deformation:

Max 9.71+000@Nd 744617

The first bending up mode of the aileron

(f)

Figure 16: Important modes of the wing. 
TABLE 5: Ten selected modes for flutter.

\begin{tabular}{|c|c|c|c|c|}
\hline Order & Name & Frequency $(\mathrm{Hz})$ & Selected (X) & Reorder \\
\hline 1 & The first rigid mode of the aileron deflection & $1.6 E-5$ & & \\
\hline 2 & The first bending mode of the wing & 9.337 & $\mathrm{X}$ & 1 \\
\hline 3 & The first translational mode of the wing & 25.73 & $\mathrm{X}$ & 2 \\
\hline 4 & The flap deflection mode $\&$ bending down mode of the aileron & 26.92 & & \\
\hline 5 & The flap deflection mode \& bending up mode of the aileron & 31.056 & $\mathrm{X}$ & 3 \\
\hline 6 & The first bending up mode of the aileron & 40.307 & $\mathrm{X}$ & 4 \\
\hline 7 & The deflection mode of the flap \& aileron & 44.25 & $\mathrm{X}$ & 5 \\
\hline 8 & The local mode of the wing & 46.21 & & \\
\hline 9 & The first torsional mode of the aileron & 60.08 & $\mathrm{X}$ & 6 \\
\hline 10 & The second torsional mode of the aileron & 65.58 & $\mathrm{X}$ & 7 \\
\hline 11 & The translational mode of the flap & 66.27 & $\mathrm{X}$ & 8 \\
\hline 12 & The first torsional mode of the flap & 73.04 & $\mathrm{X}$ & 9 \\
\hline 13 & The first torsional mode of the wing & 75.29 & $\mathrm{X}$ & 10 \\
\hline 14 & The third torsional mode of the aileron & 88.92 & & \\
\hline 15 & The second torsional mode of the wing & 91.24 & & \\
\hline 16 & The third torsional mode of the wing & 106.16 & & \\
\hline 17 & The translational mode of the flap & 112.06 & & \\
\hline 18 & The fourth torsional mode of the wing & 123.91 & & \\
\hline 19 & The second bending up mode of the aileron & 126.24 & & \\
\hline 20 & The local mode of the flap & 129.19 & & \\
\hline
\end{tabular}

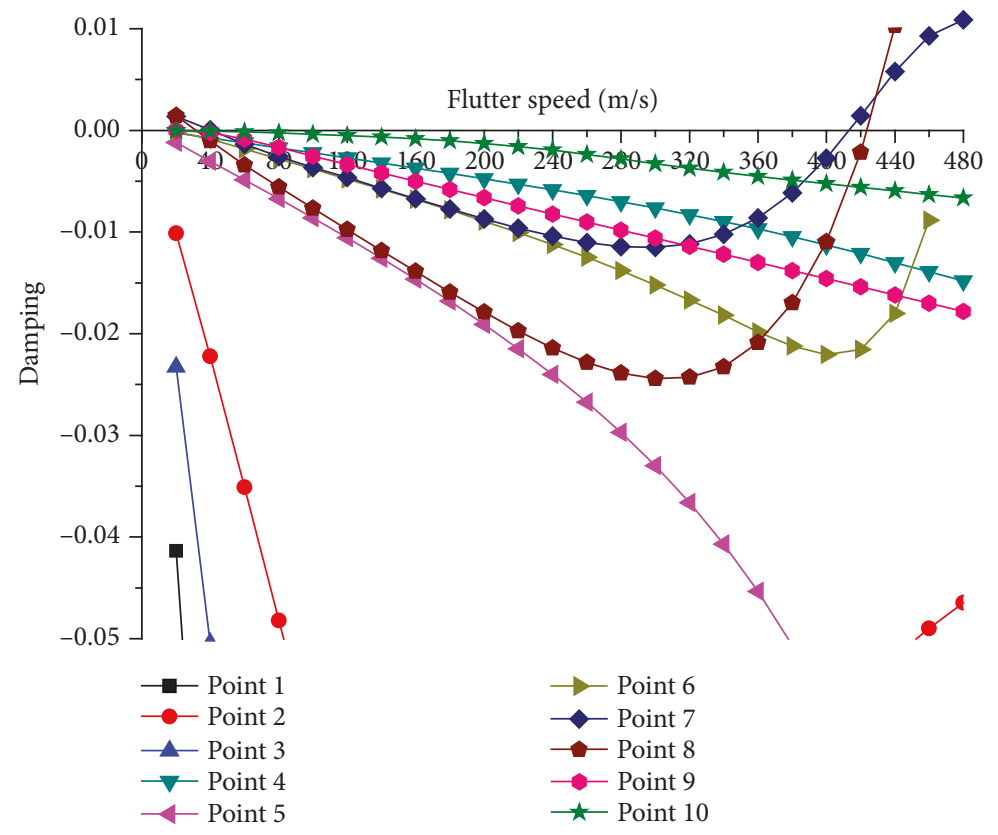

Figure 17: $V$-g curve.

methods may be considered. Firstly, the aileron is still designed with multiple joints; however, according to different flight conditions, only two joints at different positions can remain connected by relays. Secondly, the connectors working at the different flight conditions can also be reproduced in the air through the memory function of the shape memory alloy. Finally, it can also be fixed by one joint and the other can be moved to different positions by sliding rails, due to the different flight cases. Like this, the aileron's operation efficiency can be optimized.

Finally, these new aileron joints proposed are applicable to the design of new aircraft, such as high-aspect-ratio UAVs, high-aspect-ratio commercial aircraft, and flyingwing aircraft. 


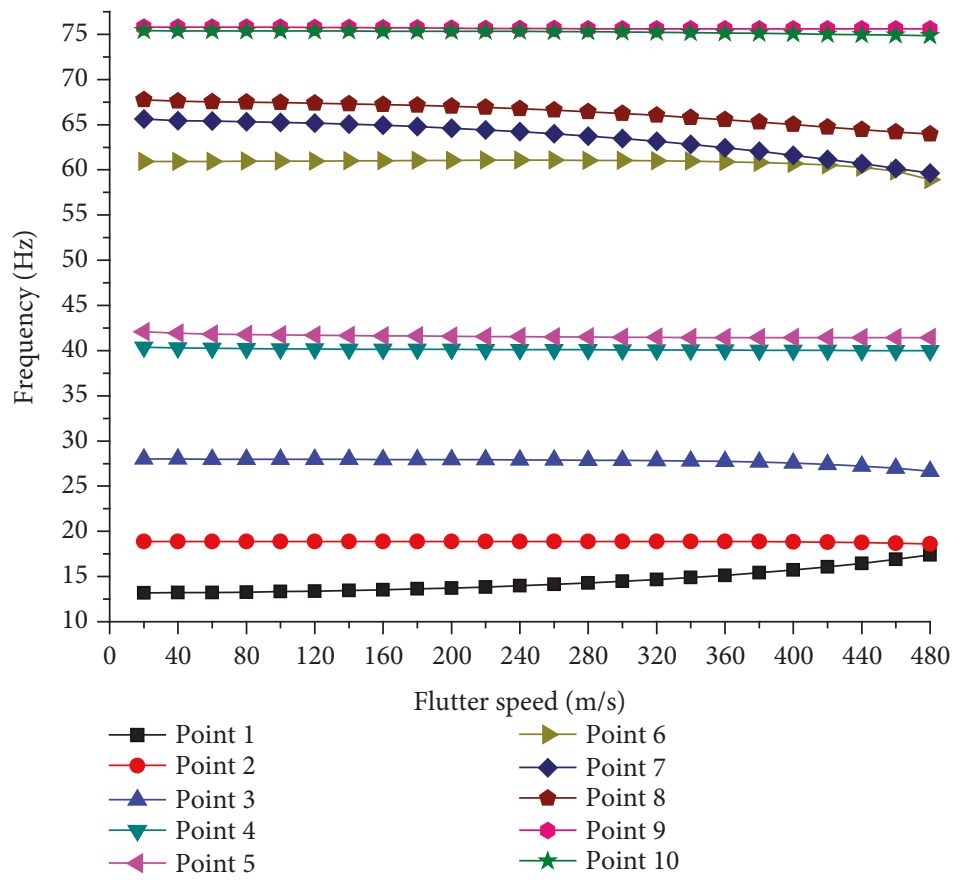

FiguRE 18: $V$-f curve.

TABLE 6: Comparison of the critical flutter speed.

\begin{tabular}{lc}
\hline Cases & Flutter speed $(\mathrm{m} / \mathrm{s})$ \\
\hline 1 & 410 \\
2 & 450 \\
3 & 460 \\
\hline
\end{tabular}

\section{Data Availability}

The beamtry6.bdf data used to support the findings of this study have been deposited in Section 3.1 of the manuscript. The ban1.bdf data used to support the findings of this study have been deposited in Section 3.2 of the manuscript. The MSC.Flightloads' workshop data used to support the findings of this study are included within the curves in Figures 2 and 3 in the manuscript. The model data in Section 3.3 and Section 3.4 used to support the findings of this study cannot be made freely available, because the model was full of too many detailed structures, though it was very old.

\section{Conflicts of Interest}

The authors declare that there is no conflict of interest regarding the publication of this paper.

\section{Acknowledgments}

The authors would like to thank the Beijing Aeronautical Science \& Technology Research Institute (BASTRI) of Commercial Aircraft Corporation of China Ltd. for supporting the development of this new technology for wing-aileron design. And also, my deepest gratitude goes to Professor Haisong Ang, working at the Nanjing University of
Aeronautics and Astronautics, for his constant encouragement and guidance, especially after my graduation. In the example of this paper, Section 3.4, he directed me to finish it. At present, the research does not receive specific funding. But this method is patented by BASTRI. The application number is CN201710995171.6; the patent disclosure and announcement number is CN108163183A.

\section{Supplementary Materials}

1: the beamtry6.bdf data used to support the findings of this study have been deposited in Section 3.1 of the manuscript. 2: the ban1.bdf data used to support the findings of this study have been deposited in Section 3.2 of the manuscript. 3: the MSC.Flightloads' workshops such as the WS_2_antisymm_2017.pdf and WS_5_flutter_ws_ swept_wing_april_2017.pdf data used to support the findings of this study are included within the curves in Figures 2 and 3 of the manuscript and show how to build the aeroelastic models step by step. 4: the background.pdf is used to introduce the background of the manuscript. (Supplementary Materials)

\section{References}

[1] P. F. Jacobs, Aileron Effectiveness for a Subsonic Transport Model with a High-Aspect-Ratio Supercritical Wing, NASA Technical Memorandum 85674, 1983.

[2] A. Suleman, C. Crawford, and A. P. Costa, "Experimental aeroelastic response of piezoelectric and aileron controlled 3D wing," Journal of Intelligent Material Systems and Structures, vol. 13, no. 2-3, pp. 75-83, 2016.

[3] A. M. Pankonien, C. T. Faria, and D. J. Inman, "Synergistic smart morphing aileron," 54th AIAA/ASME/ASCE/AHS/ASC 
Structures, Structural Dynamics, and Materials Conference, AIAA 2013-1512, 2013, pp. 1-11, Boston, MA, USA, April 8$11,2013$.

[4] A. M. Pankonien, K. Duraisamy, C. T. Faria, and D. J. Inman, "Synergistic smart morphing aileron: aero-structural performance analysis," in AIAA SciTech 22nd AIAA/ASME/AHS Adaptive Structures Conference, AIAA2014-0924, pp. 1-13, National Harbor, MD, USA, January 13-17, 2014.

[5] A. Koreanschi, G. O. Sugar, and R. M. Botez, "New numerical study of the boundary layer behavior on morphing wing-with-aileron system," in 32nd AIAA Applied Aerodynamics Conference, AIAA2014-3170, pp. 1-18, Atlanta, GA, USA, June 16-20, 2014.

[6] K. A. Makarov and A. A. Pavlenko, "Numerical investigation of an aileron hinge moments and effectiveness on a high lift wing airfoil," in 29th Congress of the International Council of the Aeronautical Sciences, pp. 1-10, St. Petersburg, Russia, September 7-12, 2014.

[7] J. B. Vincent and R. M. Botez, "Systemic modeling and design approach for morphing wing aileron controller using Matlab/Simulink," in AIAA SciTech, AIAA Modeling and Simulation Technologies Conference, AIAA2015-0904, pp. 1-10, Kissimmee, FL, USA, January 5-9, 2015.

[8] B. Johnson and R. Lind, "High angle-of-attack flight dynamics of small UAVs," in 47nd AIAA Aerospace Sciences Meeting Including the New Horizons Forum and Aerospace Exposition, AIAA2009-61, pp. 1-13, Orlando, FL, USA, January 5-8, 2009.

[9] M. Sellers and D. A. Corder, "Reduction of required wind tunnel test time through active trim during sweeps," in 47th AIAA Aerospace Sciences Meeting Including The New Horizons Forum and Aerospace Exposition, AIAA 2009-1515, pp. 1-14, Orlando, FL, USA, January 5-8, 2009.

[10] J. K. Halland and J. K. Mason, "Autonomous aileron roll control for miniature air vehicles," in Infotech@Aerospace 2012, AIAA2012-2482, pp. 1-9, Garden Grove, CA, USA, June 1921, 2012.

[11] J. Pratheepan and R. J. Bruce Ralphin, "Aileron effectiveness in the presence of aeroelastic deformations," SSRG International Journal of Mechanical Engineering, vol. 2, no. 6, pp. 12-16, 2015.

[12] A. Elham and M. J. L. van Tooren, "Tool for preliminary structural sizing, weight estimation, and aeroelastic optimization of lifting surfaces," Proceedings of the Institution of Mechanical Engineers, Part G: Journal of Aerospace Engineering, vol. 230, no. 2, pp. 280-295, 2016. 


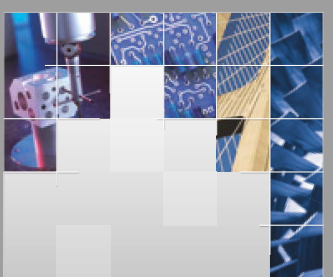

\section{Enfincering}
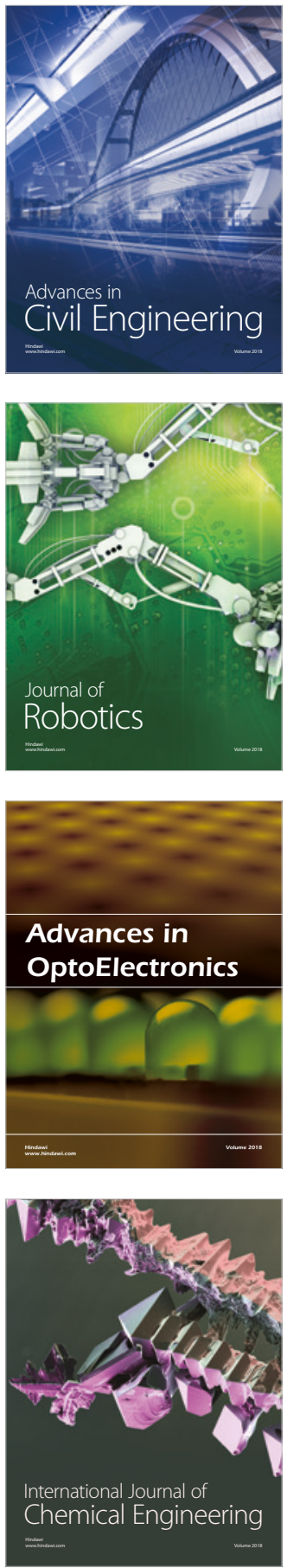

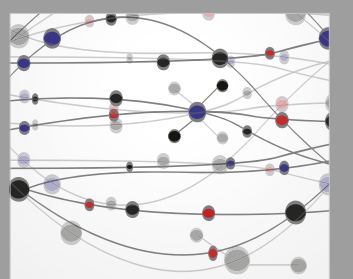

\section{Rotating \\ Machinery}

The Scientific World Journal

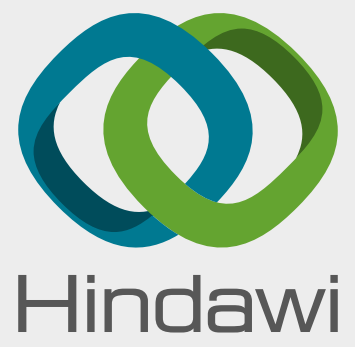

Submit your manuscripts at

www.hindawi.com
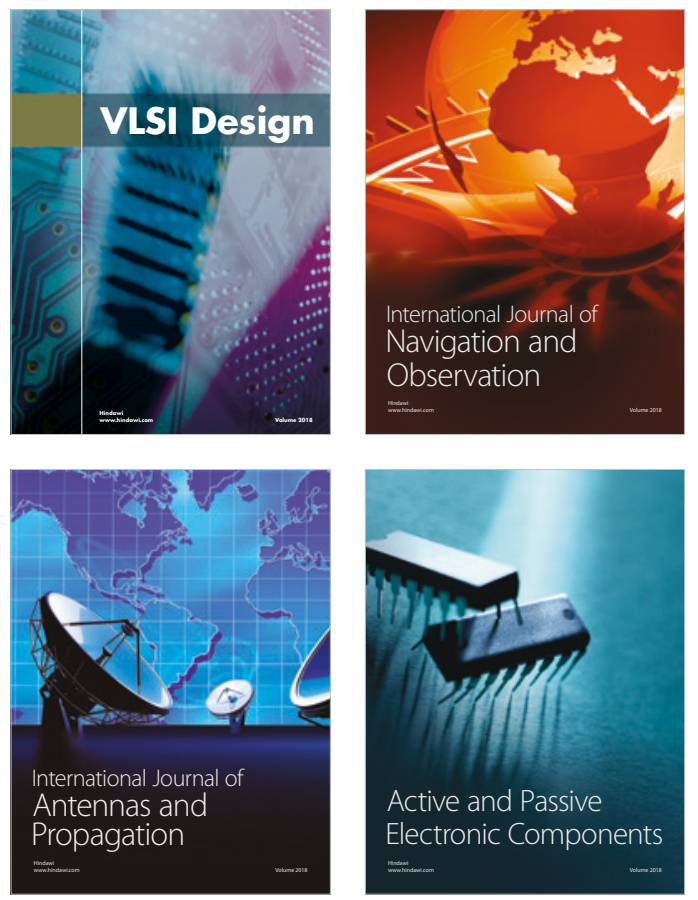
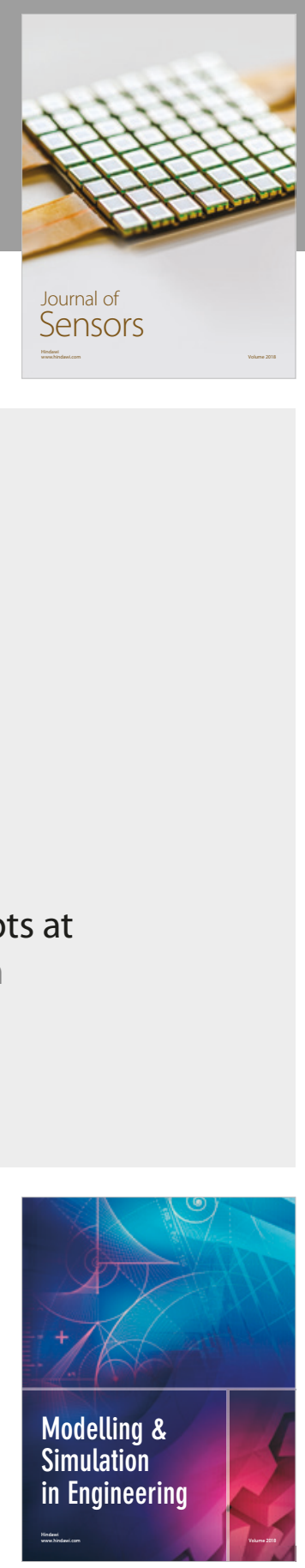

\section{Advances \\ Multimedia}
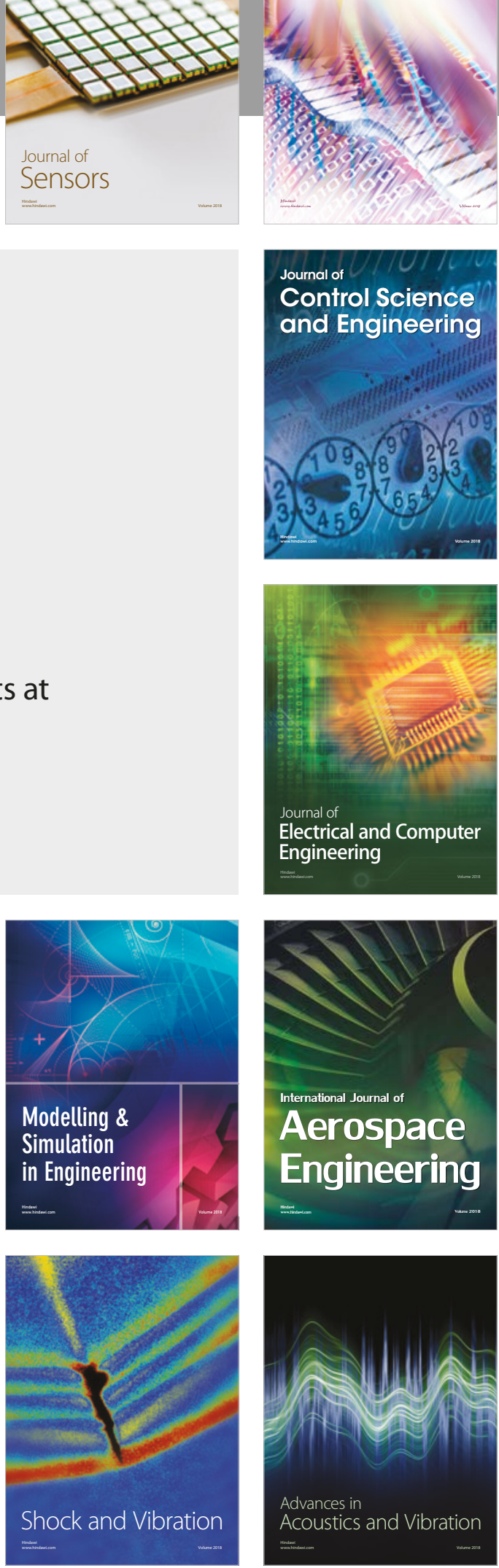